\title{
El tráfico de influencias en la Propuesta de Armonización de la Legislación Penal en la Lucha contra el Crimen Organizado en Centroamérica. Algunas consideraciones técnicas y político-criminales
}

Fernando Vázquez-Portomeñe Seijas*

Universidad de Santiago de Compostela

fernando.portomene@usc.es

Fecha de recibido: 23 de noviembre de 2015/ Fecha de aprobación: 15 de diciembre de 2015

\section{Resumen}

El principal objetivo de este trabajo es el de exponer, analizar y comparar las modalidades de tráfico de influencias contempladas en la Propuesta de Armonización de la Legislación Penal en la Lucha contra el Crimen Organizado en Centroamérica y en los principales instrumentos internacionales anti-corrupción (la Convención de Derecho penal del Consejo de Europa sobre la Corrupción, la Convención de las Naciones Unidas contra la Corrupción y la Convención de la Unión Africana sobre la Prevención y la Lucha contra la Corrupción), con vistas a obtener una imagen global del delito. Tras examinar sus aspectos clave, se formulan algunas propuestas y recomendaciones que pueden ser de utilidad a la hora de implementarlo en los países del SICA que todavía no se han decidido a criminalizarlo, o de modificar, en su caso, su disciplina legal en aquellos que sí lo han hecho. El trabajo se apoya, tanto en la información contenida en la propia propuesta y en los instrumentos anteriormente citados, como en las conclusiones alcanzadas por la literatura especializada.

\section{Palabras claves}

Corrupción pública / armonización de la legislación penal / Latinoamérica / tráfico de influencias

\section{The crime of influence peddling in the Proposal for the Harmonization of Criminal Legislation in the Fight Against Organized Crime in Central America. Some technical and political criminal considerations}

\section{Abstract}

The main objective of this work is to expose, analyze and compare the forms of influence peddling included in the Proposal for the Harmonization of Criminal Legislation in the Fight Against Organized Crime in Central America and in the main international anti-corruption instruments (criminal Law Convention of the Council of Europe on Corruption, the UN Convention against Corruption and the African Union Convention on Preventing and Combating Corruption), in order to obtain an overall picture of this crime. After examining its key issues, proposals and recommendations that may be useful when implementing it in the SICA countries that have not yet decided to criminalize it are formulated. The work is based both on the information contained in the Proposal and in the above mentioned instruments, and the conclusions reached by the technical literature.

* El autor es Profesor Titular de Derecho Penal de la Universidad de Santiago de Compostela 
Public corruption / harmonization of criminal legislation / Latin America / influence peddling

Tabla de contenido

I. Introducción. II. La PALCO y su contexto. III. EI tráfico de influencias en los instrumentos internacionales anti-corrupción. I. La Convención de Derecho penal del Consejo de Europa sobre la Corrupción. 2. La Convención de las Naciones Unidas contra la Corrupción. 3. La convención de la Unión Africana sobre la Prevención y la Lucha contra la Corrupción. IV. Elementos del delito en la PALCO y en las convenciones internacionales anti-corrupción. 4.I. Modalidades de conducta. 4. 2. El abuso de influencia. 4.3. Diferencias entre el tráfico y el lobbying. 4.4. Las dádivas. V. Conclusiones. Referencias bibliográficas

\section{Introducción}

Diversos estudios empíricos demuestran que existe una correlación significativa entre los niveles de corrupción y magnitudes como la distorsión de la composición del gasto público y la reducción del nivel de inversión extranjera directa $^{79}$, haciendo de aquella, en consecuencia, un problema de primer grado en las sociedades modernas. El establecimiento de una cultura corporativa ética y la implementación de estrategias anticorrupción sólidas, dirigidas a lograr que las empresas puedan considerarse "dignas de confianza" a la hora de participar en licitaciones públicas, por ejemplo, trasciende claramente al plano de la esfera privada empresarial, para repercutir en el funcionamiento de los mercados y el crecimiento económico (Fundación Ecología y Desarrollo. 2013, pp. 38 y ss.). Por esa razón, aunque corresponde a cada país la tarea de encontrar soluciones a la corrupción ajustadas a su propia realidad normativa, económica y sociológica ${ }^{80}$, la internalización y armonización de los mercados debería conducir a la adopción de estrategias y marcos de actuación comunes ${ }^{81}$. En esa línea, expertos, investigadores y organizaciones internacionales han venido alertando sobre los efectos negativos de las políticas anti-corrupción "asimétricas" en el comercio internacional y en el funcionamiento de los mercados e insistiendo en la necesidad de definir marcos legales consistentes y precisos, que no dejen margen a las autoridades y funcionarios para dispensar trato de favor a particulares, grupos o empresas (Wesberry, 2004, pp. 6 y ss.).

Todas las consideraciones que acaban de hacerse no han impedido que buena parte de los instrumentos internacionales anti-corrupción hayan excluido al tráfico de sus previsiones, y que los que sí dan entrada a medidas o recomendaciones relacionadas con él, hayan sido objeto de no pocas controversias relacionadas con su ámbito de aplicación y con la técnica legal empleada en su descripción. La mejor prueba de ello es que, de los 43 Estados que ratificaron la Convención del Consejo de Europa contra la Corrupción, más de una cuarta parte formularon reservas a la recomendación de sancionarlo penalmente, con diversos argumentos examinados por el Grupo de Estados contra la Corrupción en su tercera ronda de evaluación: la suficiencia de otras figuras, como el cohecho o el abuso de confianza contra la empresa, para lidiar con todos los supuestos de influencias ilícitas; la posible colisión entre la criminalización del tráfico de influencias y la autorización legal para que ciertos colectivos, organizaciones no gubernamentales o grupos de interés intenten ejercer influencias (políticas o financieras) y plantear -también personalmente, mediante encuentros o contactos con las autoridades o funcionarios- iniciativas

${ }^{79}$ DEL PINO (2007, pp. 6 y 7); REÁTEGUI SÁNCHEZ (2004, p. 2); KLITGAARD (1994, pp. 52 y ss.); TANZI (2002, p. 45); MALEM SEÑA (2002, p. 69).

${ }^{80}$ PEÑAILILLO, ARAÚZ, SALDOMANDO Y BERTHIN (2009, pp. 91 y ss.); MALEM SEÑA (2002, p. 69); TAY Y SEDA (2003, p. 7). PEÑAILILLO (2009, p. 32) insiste en la multiculturalidad y realidad propias de cada uno de los Estados partes en las convenciones anticorrupción como factor condicionante de su proceso de implementación y seguimiento.

${ }^{81}$ BAENA, BASCO Y DE MICHELE (2010, pp. 3 y ss.); LOMBANA VILLALBA (2013, p. 18). 
de defensa de sus intereses; $y$, por último, la complicada estructura del delito y la falta de claridad de los términos en que se expresa el art. 12 de la mencionada Convención a la hora de establecer sus elementos.

La perspectiva con que la Propuesta de Armonización de la Legislación Penal en la Lucha contra el Crimen Organizado en Centroamérica (en adelante PALCO) examina dicho fenómeno delictivo es, en cambio, muy distinta $y$, desde luego, menos restrictiva, al presentarlo como una modalidad principal de corrupción pública, con una capacidad considerable para lesionar o dañar la confianza de los ciudadanos en el correcto funcionamiento de las instituciones (COMJIB, 20II, pp. II6 y ss.).Sus autores se reafirman así, en todo momento, en la conveniencia de criminalizarlo, poniendo sobre la mesa cuestiones como su relación con el cohecho o la necesidad de seleccionar técnicas de tipificación adecuadas para incorporarlo a los sistemas penales nacionales.

El principal objetivo de este trabajo es el de exponer, analizar y comparar las modalidades de tráfico de influencias contempladas en dicha propuesta y en los principales instrumentos internacionales anti-corrupción (la Convención de Derecho penal del Consejo de Europa sobre la Corrupción; la Convención de las Naciones Unidas contra la Corrupción, el único instrumento con vocación verdaderamente universal en esta materia; y la Convención de la Unión Africana sobre la Prevención y la Lucha contra la Corrupción), con vistas a obtener una imagen global del delito. Al examinar la estructura y la literalidad de las correspondientes previsiones podremos determinar qué prácticas pueden encontrar cobertura en ellas. La elección del tema se justifica, además, por el dato de que la extradición -mecanismo básico de cooperación internacional en el ámbito criminal- se fundamenta en el principio de identidad de los criterios de incriminación, resultando, en consecuencia, sumamente relevante conocer cuáles son los modelos de criminalización que se desprenden de las convenciones internacionales y su grado de compatibilidad y homogeneidad (Del Pino, 2007, Pp. 3 y ss.). Por último, examinar los aspectos clave de la regulación del tráfico en la PALCO nos permitirá formular propuestas y recomendaciones que pueden ser utilidad a la hora de implementarlo en los países del SICA que todavía no se han decidido a criminalizarlo, o de modificar, en su caso, su disciplina legal en aquellos que sí lo han hecho. El trabajo se apoyará, tanto en la información contenida en la propia propuesta y los instrumentos anteriormente citados, como en las conclusiones alcanzadas por la literatura especializada.

En las páginas que siguen se considerarán, por este orden: (I) las modalidades de conducta; (2) el abuso de influencia, como medio comisivo; y (3) el concepto de "ventaja indebida". Se aludirá, además, al tratamiento recibido por el lobbying. Con carácter previo, se realizará una breve reseña de la génesis y sentido general de la PALCO y se irán presentando los instrumentos, por orden cronológico de su adopción.

\section{La PALCO y su contexto}

Las dinámicas, perfiles y consecuencias de la corrupción en Latinoamérica han sido objeto de números estudios. Se ha destacado, por ejemplo, que las dinámicas de liberalización, armonización y desregulación de los mercados han alterado los procesos de toma de decisiones políticas y económicas, trayendo consigo modificaciones sustanciales en las funciones y responsabilidades de los actores involucrados y en sus estrategias competitivas ${ }^{82}$, y que, en este contexto, las empresas encuentran enormes incentivos para tratar de condicionar o influir en los funcionarios y representantes gubernamentales (ver reforzada su posición en el mercado a través de decisiones en materia de fusión de empresas o reestructuración de sectores económicos, obtener ventajas competitivas por medio de normas que distorsionen la formación de precios o el sistema de selección en la contratación, beneficiarse de nuevas ventajas o exenciones fiscales... ${ }^{83}$. También se ha venido analizando la aparición, en el subcontinente, del fenómeno denominado "captura del Estado", definido por el Banco Mundial como "las acciones de los individuos, grupos o empresas, en los sectores público y privado, para influir en la formación de las leyes, reglamentos, decretos y otras políticas gubernamentales para su propio beneficio, como resultado de la atribución

\footnotetext{
${ }^{82}$ PEÑAILILLO, ARAÚZ ULLOA, SALDOMANDO Y BERTHIN (2009, pp. 29 y ss.).

${ }^{83}$ VARGAS-HERNÁNDEZ (2012, p. 13); SOREIDE (2014, pp. 239 y 240).
} 
ilícita y no transparente de beneficios privados a funcionarios públicos”, acreditándose su enorme impacto en términos económicos, políticos $y$, también, sociales ${ }^{84}$.

Es en este contexto en el que adquiere todo su significado la PALCO. Incluida en el Plan Estratégico realizado por la Secretaría General de la Conferencia de Ministros de Justicia de los Países lberoamericanos (COMJIB), su objetivo primordial es el de abordar la lucha contra la delincuencia más grave de la mano de un proceso de unificación de la legislación procesal y de armonización de los tipos relativos a los delitos de cohecho, tráfico de influencias y peculado, entre otros, en los países miembros del SICA. El documento fue revisado, debatido y validado en un taller técnico desarrollado en San Salvador, los días 8, 9 y 10 de junio de $201 \mathrm{I}$.

\section{El tráfico de influencias en los instrumentos internacionales anti-corrupción}

\section{La Convención de Derecho penal del Consejo de Europa sobre la Corrupción}

La Convención de Derecho penal del Consejo de Europa sobre la corrupción (en adelante CCE) fue adoptada el 4 de noviembre de 1998, entrando en vigor el I de julio de 2002, tras haberse alcanzado el número de 14 ratificaciones. Está abierta para ser firmada por los estados miembros del Consejo de Europa y por otros seis no miembros, pero que participaron en su elaboración (Bielorrusia, Canadá, Santa Sede, Japón, México, Estados Unidos de América). También pueden recibir la invitación para ser parte en ella terceros estados y la Unión Europea. A la altura de mayo de 2015 ha sido firmada por un total de cincuenta estados y ratificada por cuarenta y cinco.

Sus pilares son la armonización de las normas europeas concernientes a delitos de corrupción y la capacitación técnica de los estados contratantes, a través de programas de cooperación, para prevenirla y perseguirla y entre sus objetivos prioritarios se cuenta el desarrollo del espectro de medidas penales anti-corrupción. Ese es el sentido de las obligaciones de criminalización descritas en el Capítulo II ("Medidas que deben ser adoptadas a nivel nacional”), referidas, entre otras figuras, al tráfico de influencias en el sector público (art. 12).

El tráfico viene considerado como una forma de corrupción muy vinculada al cohecho, con el que comparte bien jurídico (la transparencia e imparcialidad de los funcionarios y autoridades públicas) y función (evitar que se genere una atmósfera de corrupción en la sociedad). Tal y como indica el párrafo 64 del Informe Explicativo de la Convención, su inclusión en la legislación interna permite prevenir las prácticas corruptas de quienes se mueven en los entresijos del poder, sirviendo para sancionar a quienes tratan de aprovecharse de su proximidad a los funcionarios (nacionales o internacionales), a los miembros de los parlamentos (nacionales e internacionales) $\circ$ a los partidos políticos para enriquecerse u obtener ventajas o privilegios.

Con todo, y a pesar de los términos imperativos en que se expresa el precitado art. 12, el art. 37 de la CCE les permite a las partes reservar (en el momento de la firma o del depósito de los instrumentos de ratificación, aceptación, aprobación o adhesión) su derecho a no establecer como delito, en todo o en parte, las conductas previstas en los artículos 4, 6 a 8, 10 y 12, así como el cohecho pasivo previsto en el 5. El control de cumplimiento con la convención compete al Grupo de Estados contra la Corrupción (GRECO), que inició sus tareas el I de mayo de 1999.

\footnotetext{
${ }^{84}$ Llama la atención el hecho de que bastantes de los sistemas penales de la región contienen una regulación excesivamente parca de los delitos de tráfico de influencias. Nicaragua, Guatemala, Colombia u Honduras, por ejemplo, se limitan a castigar a los funcionarios o particulares que hacen uso de sus influencias, derivadas del cargo o de otras relaciones, para obtener un beneficio económico para si o para un tercero.
} 


\section{La Convención de las Naciones Unidas contra la Corrupción}

Con la finalidad de conformar las legislaciones nacionales, a través del establecimiento de un lenguaje y líneas de actuación comunes, y de facilitar la cooperación internacional y la asistencia técnica, el 3 I de Octubre de 2003 la Asamblea General de las Naciones Unidas aprobó la resolución 58/4, adoptando la Convención de las Naciones Unidas contra la Corrupción (en adelante UNCAC). Se trata del más detallado y extenso de los instrumentos globales destinados a prevenir y combatir la corrupción pública. Incorpora, entre otras, previsiones relacionadas con la criminalización de ciertas conductas (Capítulo III, arts. I5 y ss.), la extradición (Capítulo IV, art. 44), la asistencia mutua (Capítulo IV, art. 46), la prevención y detección de transferencias de los beneficios derivados de la corrupción (Capítulo V, art. 52) y la recuperación de propiedades a través de la cooperación internacional en relación con el decomiso de los beneficios de la corrupción (Capítulo $\mathrm{V}$, art. 54). Al requerir treinta ratificaciones para llegar a ser vinculante, de acuerdo con su art. 68, no entró en vigor hasta el 14 de diciembre de 2005. En mayo de 2015 el número de firmantes se eleva a ciento cuarenta y el de estados que lo han ratificado a ciento setenta y cinco.

Aunque presenta al tráfico de influencias como un instrumento esencial para prevenir interferencias en los procedimientos de adopción de decisiones en el sector público, la UNCAC no impone su tipificación. En el transcurso de los trabajos preparatorios, el comité ad hoc para la negociación de la convención sí había apostado, en el borrador de su primera sesión, por su criminalización obligatoria. No obstante, aunque las iniciativas presentadas por Francia, México, Colombia, Turquía y Filipinas apoyaron esa solución, y, durante la primera lectura, otras delegaciones expresaron su preferencia por ella, en la sexta sesión se adoptó otra propuesta que consagraba su carácter no vinculante, defendida por Canadá, Francia e Italia. Los motivos que llevaron a la mayoría de las delegaciones a decantarse por ella fueron dos: la amplitud del objeto del delito, tal como resulta definido en el art. 18; y el hecho de que los códigos penales de muchos países (por ejemplo los de los Estados Unidos y Alemania) carecen de una figura semejante. Hay que tener en cuenta, además, que la convención usa numerosas cláusulas de salvaguarda y de sujeción de diversas previsiones a principios de derecho nacional -concediéndole, por ejemplo, a los estados contratantes la posibilidad de garantizar la inmunidad a (antiguos) funcionarios corruptos-, lo que redunda en la falta de efectividad del precepto.

Durante la Conferencia de estados partes de Qatar, en 2009, se acordó la creación de un mecanismo de fiscalización de la implementación de la UNCAC. En virtud de él, los estados serán fiscalizados cada cinco años, a partir de procesos de autoevaluación y de visitas de especialistas internacionales. Los resultados de las evaluaciones se recogen en informes nacionales, cuyo sentido es el de mostrar el grado de cumplimiento de los compromisos adquiridos.

\section{La convención de la Unión Africana sobre la Prevención y la Lucha contra la Corrupción}

El último de los instrumentos internacionales que compromete a las partes a criminalizar el tráfico de influencias es la Convención de la Unión Africana sobre la Prevención y Lucha contra la Corrupción (en adelante CUA), adoptada por la Cumbre de los Jefes de Estado de la Unión Africana, en Maputo, el I I de Julio de 2003. Su entrada en vigor se produjo el 5 de Agosto de 2006, estando abierta a la firma de los cincuenta y cuatro estados miembros de la Unión Africana. A la altura de mayo de 2015, había sido firmada por cuarenta y ocho, habiendo sido ratificada por treinta y cinco.

La CUA persigue impulsar, a nivel nacional, un proceso de criminalización armonizada de determinados actos de corrupción, listando (y describiendo) para ello un conjunto de prácticas y figuras, entre las que se cuentan el cohecho activo y pasivo y el tráfico de influencias. Todas ellas vienen sometidas a un mismo régimen de tipificación obligatoria por parte de los estados contratantes. 
El objeto de la convención es la corrupción en los sectores público y privado, a gran y a pequeña escala. Su régimen de obligaciones apunta a los terrenos de la prevención, la criminalización y la cooperación entre las partes. A tal efecto, contiene previsiones -muy ambiciosas- en materia de jurisdicción (art. 13), extradición (art. I5), confiscación e incautación de activos (art. 16), levantamiento del secreto bancario (art. 17) y asistencia legal mutua y cooperación internacional (art. 18). Con todo, su alcance se ve recortado, de nuevo, por la incorporación de cláusulas de salvaguarda, que terminan por condicionar la vigencia de ciertas previsiones a lo que establezcan las legislaciones nacionales. El art. 24. I, por ejemplo, permite que, en el momento de la adopción, firma, ratificación o adhesión, cualquier Estado pueda hacer reservas relativas a una o varias disposiciones en concreto, con el único límite de que no sean incompatibles con el objeto y objetivos de la convención. Lo mismo sucede con lo establecido, a propósito de la inmunidad de los funcionarios corruptos, por el art. 7. I, sujeto, también, a lo que puedan arbitrar las partes a nivel interno.

El control del cumplimiento de los compromisos de los estados viene encomendado al Consejo Asesor sobre Corrupción constituido en el seno de la Unión Africana (UA), integrado por once expertos. Dicho órgano deberá informar, sobre ese particular, al Consejo Ejecutivo de la UA, siempre sobre la base de los informes presentados por las agencias nacionales anti-corrupción. A pesar de ello, ni posee poderes investigadores, ni viene facultado para denunciar actos de corrupción o para sancionar a los estados cuando sus agencias no aportan los informes correspondientes. Además, la independencia de sus integrantes es discutible, en la medida en que vienen propuestos por los estados mismos. La debilidad de este sistema de control ha llevado a sugerir que la CUA se transforme en un Protocolo a la Convención Africana sobre Derechos Humanos y de los Pueblos, lo que tendría el resultado de someter sus previsiones anti-corrupción a la competencia de la Comisión Africana y de la Corte Africana de los Derechos Humanos y de los Pueblos.

\section{Elementos del delito en la PALCO y en las convenciones internacionales anti-corrupción}

\section{I. Modalidades de conducta}

Al igual que los restantes instrumentos analizados, la PALCO alude a la existencia de una relación triangular de carácter corrupto, en la que un sujeto pone por delante su capacidad para interferir en el proceso que debe llevar a una autoridad o a un funcionario a adoptar una decisión (administrativa, judicial o política). En lo que sí muestra ciertos rasgos distintivos es a la hora de precisar las conductas típicas del tráfico de influencias.

Así, y a diferencia de las tres convenciones examinadas, desconoce lo que suele denominarse "tráfico activo", es decir, la promesa, el ofrecimiento o la dación -directa $\circ$ indirectamente- de una ventaja indebida, a un intermediario, a cambio del ejercicio de influencias ${ }^{85}$. La necesidad de proteger a la Administración Pública, no pasa, entonces, según la PALCO, por la tipificación de esas modalidades, cuya consumación no requiere que haya comenzado a ejercerse la influencia y que implican, en dos de los casos -el de la promesa y el de la dación- un elemento quid pro quo: que se hayan convenido el ejercicio de la influencia y su retribución (COMJIB, 20I I, PP. 119 y 120).

Con respecto al tráfico pasivo, la UNCAC y la CUA lo asocian a las conductas de solicitar y aceptar una ventaja, a modo de contraprestación, por el abuso de la influencia, en tanto que la CCE contempla también la de recibir. La solicitud es, como se sabe, un acto unilateral, a través del que el intermediario le da a conocer al cliente su disposición a utilizar, en beneficio de aquel, y a cambio de un precio, sus influencias. La aceptación y la recepción representan, en cambio, actos bilaterales, que implican un acuerdo (no necesariamente duradero o estable) entre

\footnotetext{
${ }^{85}$ En los ordenamientos latinoamericanos, en algunos casos únicamente se prevé la conducta de solicitar de tercero dádiva para influir (El Salvador, Panamá). En otros (como en Perú) se castiga en el mismo precepto recibir, hacer dar o prometer para sí o para un tercero, donativo o promesa o cualquier otra ventaja o beneficio con el ofrecimiento de interceder ante un funcionario o servidor público.
} 
las partes. La PALCO no parece ir más allá, sin embargo, de recomendar la criminalización la conducta de quien "ofreciéndose a realizar conductas de tráfico de influencias, solicita de terceros dádivas" (COMJIB, 20I I, P. II9).

Otro elemento común a las tres convenciones, pero sobre el que la PALCO guarda silencio, es que no requieren una forma personal de realización del delito, sancionando expresamente la tipicidad de las conductas llevadas a cabo por personas interpuestas. Estas últimas -que intervienen en nombre del autor estableciendo relaciones e interviniendo en las negociaciones con el comprador o recibiendo la dádiva- desempeñan un papel especialmente importante en el hecho, debiendo corresponderles, normalmente, la calificación de cooperadoras necesarias.

Tampoco se pronuncia, finalmente, acerca de si el precio de la compra-venta debe aprovecharle, exclusivamente, al sujeto que va a ejercer la influencia o si caben otras opciones. Ni la UNCAC, ni la CCE lo exigen. Los términos "para cualesquiera otras personas", incluidos en ambas, indican claramente, por el contrario, que su beneficiario puede ser un miembro de su familia o un amigo, siempre y cuando el intermediario lo conozca y consienta. Aunque del tenor literal del art. I8 UNCAC parece desprenderse la idea de que la ventaja sólo puede ser recibida por una persona física, los autores de su Guía Legislativa parten de la base de que también puede entregarse al partido político, entidad u organización a que pertenece. El art. I 2 de la CCE suscita la misma problemática: a pesar de no mencionarlas, los autores del Informe Explicativo identifican a las entidades como posibles beneficiarios, guarden o no relación con el intermediario. Si los beneficiarios conocían el origen ilícito de la ventaja, podrán responder como cómplices, y si, además, realizan labores de intermediación en el negocio (con el comprador), lo harán como cooperadores necesarios.

\section{2. El abuso de influencia}

Al igual que la CCE y la CUA, la PALCO pone en conexión, en la descripción del delito, el ejercicio de la influencia con un proceso de toma de decisiones (COMJIB, 20l I, p. I I9). Por lo que alcanzo a ver, el único instrumento que no lo hace es la UNCAC, cuyo art. 18 se limita a contemplar la entrega o aceptación de ventajas para influir en una autoridad o funcionario y lograr de él, así, un beneficio para el propio instigador o para un tercero.

En lo que sí se aparta de las tres convenciones internacionales examinadas en este trabajo es a la hora de (no) pronunciarse sobre la tipicidad del tráfico con influencias falsas o supuestas (venta de humo). Para ellas, el único que debe asociar (subjetivamente) la dación o recepción de la ventaja con un ejercicio real e ilegítimo de influencias es el "comprador". El "vendedor" o intermediario puede proyectar una imagen (falsa) de proximidad a los cargos públicos, simplemente, para enriquecerse a costa de los deseos de su "cliente". La PALCO no contiene, sin embargo, precisión alguna sobre el particular: ni requiere la posesión de una capacidad real de influencia, por parte del intermediario, ni alude expresamente a los casos en que aquel meramente afirma estar en condiciones de ponerla en práctica. Con todo, hay que conceder que su voluntad de alinear el delito con los esfuerzos "por proteger a la Administración Pública y asegurar que sus resoluciones se dictan con la necesaria objetividad, imparcialidad y probidad por parte de los funcionarios a su servicio" (COMJIB, 20II, p. II9). se compadece mejor -mucho mejor- con la compraventa de influencias reales que con la criminalización del tráfico con influencias falsas ${ }^{86}$. Esta segunda opción situaría el interés que se trata de proteger sobre otro plano muy distinto, el de la necesidad de reforzar la confianza de la ciudadanía en la imparcialidad de los funcionarios o de evitar la imagen de una administración endeble e influenciable ${ }^{87}$.

La criminalización de la venta de influencias falsas depara no pocos problemas. Por una parte, los estados que acojan (o hayan acogido) ese modelo deberán ajustar las relaciones normativas entre el propio tráfico y la estafa, que es la figura que, en principio, debería calificar los supuestos en que, tras sucumbir a los engaños del intermediario, en relación con la posesión de influencias, el "comprador" remunera las (falsas) gestiones y sufre el

\footnotetext{
${ }^{86}$ GUIMARAY MORI (2009, p. 116); RODRÍGUEZ DELGADO (2006, pp. 6 y 7).

87 GUIMARAY MORI (2009, p. 116); HURTADO POZO (2006, p. 288); ORA SOSÉ (2011, pp. 11 y 12); RODRÍGUEZ DELGADO (2006, pp. 7 y 8).
} 
correspondiente perjuicio patrimonial. En otro sentido, conviene recordar que la clave para poder poner en conexión el tráfico de influencias con el bien jurídico "función pública" está en su objeto: el ejercicio de influencias ante autoridades o funcionarios, como contraprestación "in fieri" a la entrega o promesa de entrega de una ventaja económica. El que la influencia que se ofrece no sea real hace que nos veamos obligados a proporcionarle un nuevo contenido ofensivo, so pena de tener que anticipar en exceso la intervención penal en el ámbito de la corrupción pública. Ahora bien, perviven serias dudas acerca de la necesidad de proteger penalmente la imagen o reputación de los aparatos estatales, el bien jurídico que parece situarse en su trasfondo. Con arreglo a ese punto de vista, por consiguiente, la disciplina de la PALCO se compadece mucho mejor con los requerimientos del principio de intervención mínima del Derecho penal.

En los sistemas penales latinoamericanos, la regulación del tráfico de influencias suele estar unida a la obtención de un beneficio económico como resultado del delito, lo que implica que, en los supuestos en que no llega a conseguirse, únicamente podría hablarse de tentativa. Algunos ordenamientos (caso de Nicaragua) construyen el tipo, en cambio, como de resultado cortado, siendo suficiente con que el sujeto activo aliente esa finalidad para considerarlo consumado. Por último, Perú y Argentina han optado por desvincularlo tanto de dicha intención, como del resultado, para asociarlo, únicamente, a la intercesión ante el funcionario o servidor público que haya conocido, esté conociendo o vaya a conocer un caso judicial o administrativo (Perú) o a la solicitud o recepción de dinero o de algún otro beneficio a cambio influir indebidamente ante un funcionario para que haga, retarde $\circ$ deje de hacer algo relativo a sus funciones (Argentina).

La regulación internacional del tráfico tampoco ve preciso que la influencia -el objeto de la compraventa- llegue realmente a ejercerse (ante la autoridad o funcionario de que se trate), ni, mucho menos, que conduzca al resultado deseado por el "cliente". El único instrumento que no hace mención expresa de ese dato es, de nuevo, la UNCAC, pero, en la medida en que, como acaba de verse, también criminaliza la venta de influencias falsas, lo razonable es pensar que asume el mismo planteamiento. Por su parte, y en esa misma línea, la PALCO declara explícitamente que configurarlo como un delito de resultado, asociando este a la obtención de un beneficio económico, "restringe excesivamente el enunciado del artículo 18 de la Convención de NN.UU. contra la Corrupción" (COMJIB, 20II, pp. II8 y I19). Por ello, avalando la solución adoptada por el art. 450 del Código penal de Nicaragua, apuesta por darle al tráfico la estructura de los delitos de resultado cortado, siendo suficiente para su consumación, por lo tanto, "con que el sujeto aliente una finalidad para considerarse el delito consumado" (COMJIB, 20II, p. II8). El que el interesado lograse, efectivamente, el beneficio económico perseguido podría suponer, a lo sumo, una causa de agravación de la pena, al igual que la "calidad del sujeto activo" o sus relaciones con el influenciado (COMJIB, 20II, p. I20).

Desde el momento en que permite que el intermediario sea, también, un funcionario, es evidente que, con arreglo a la PALCO, el tráfico pasivo podrá desarrollarse tanto en un ámbito particular, personal, como en conexión con el desempeño de las funciones públicas. En este sentido, y aunque no concreta en ningún momento el tipo de relación que debería existir entre el ejercicio de la influencia y la condición pública del intermediario o las funciones que ejerce, lo lógico es concebirla en términos amplios, de modo que cubra la venta de influencias derivadas de la posición ocupada por aquel o que se hallen relacionadas, de alguna manera, con su trabajo o con su capacidad para acceder y manipular (por los medios que sea, también personales, afectivos...) a otra autoridad. Ahora bien, es indiscutible que cuando un funcionario instrumentaliza facultades o modos de relación propios de su cargo, para influir en otra autoridad o funcionario, está dando vida, al propio tiempo, a un delito de cohecho (solicitud o aceptación de una ventaja a cambio de la realización de una actuación contraria a los deberes inherentes al cargo) (Bonilla, 20I I, p. 25). La PALCO nos sitúa, pues, ante un fenómeno de colisión de normas, que podrá solventarse, en favor del tráfico, acudiendo al principio de especialidad.

Por lo que se refiere al sujeto pasivo de la influencia, en las previsiones de la CCE viene identificado con los funcionarios nacionales y extranjeros (arts. 2 y 5), miembros de parlamentos nacionales y extranjeros (arts. 4 y 6), funcionarios de organizaciones internacionales, miembros de asambleas parlamentarias nacionales o jueces $y$ 
funcionarios de tribunales internacionales (arts. 9 a II). En cambio, la UNCAC lo alinea con cualquier administración o autoridad pública de un Estado parte -términos que, por cierto, no vienen definidos, como tales, en la propia convención-, y la CUA con "cualquier persona que ejerce funciones en el sector público o privado". El único términos utilizado por la PALCO a tal efecto es el de "funcionario", cuyo alcance no es, en principio, más restringidos que los empleados por los convenios, puesto que puede abarcar todas las situaciones contempladas por aquellos, incluso el caso de los funcionarios extranjeros y de los miembros de los parlamentos nacionales o extranjeros que ejercen poderes legislativos o administrativos.

\subsection{Diferencias entre el tráfico y el lobbying}

Durante los procesos de elaboración de la UNCAC y de la CCE, varios estados expresaron su deseo de no penalizar el tráfico de influencias, haciendo advertencia expresa del riesgo de colisión con el desarrollo de actividades políticas plenamente legítimas. Haciéndose eco de esas dudas, el Informe Explicativo dejó sentada la idea de que la criminalización del tráfico no podía afectar, en absoluto, a las prácticas reconocidas de lobbying. En ese orden de cosas, el sentido del término "impropia", que sirve para calificar a la influencia en el art. 12 de la CCE y el 4 (I) (f) de la CUA, parece ser el de diferenciar las influencias legítimas de las ilegítimas, revistiendo, por ello, enorme trascendencia a la hora de excluir las formas autorizadas de lobbying del ámbito de aplicación del delito. La PALCO, en cambio, no define el elemento de la influencia más allá de ponerlo en relación el delito con la necesidad de proteger a la Administración Pública y de asegurar que sus resoluciones se dictan con la necesaria objetividad, imparcialidad y probidad. Esa es la única referencia utilizable a la hora de examinar la cuestión de la posible colisión del tipo con prácticas legales de lobbying.

Como es sabido, la relevancia jurídico-penal de dicho fenómeno no es un tema pacífico ${ }^{88}$. Los lobbies financieros, muy cercanos a las autoridades gubernamentales, pueden obtener grandes beneficios interfiriendo, en interés propio, en las decisiones más importantes en el ámbito de la política comercial, la ordenación de los mercados o la competencia, así como en los criterios de adjudicación de grandes contratos -como los relacionados con las infraestructuras-89. Está claro, no obstante, que no todos los grupos de presión velan por intereses particulares. Los lobbies sociales, por ejemplo, llevan a cabo una encomiable labor, normalmente con medios muy limitados, para conseguir mejorar las condiciones de acceso a los servicios sociales de determinados grupos de población.

El acceso de los lobbies al ámbito de lo penalmente relevante no se produce, por lo tanto, por el simple hecho de propiciar actividades de intermediación ante las autoridades y responsables políticos, sino a partir de los objetivos perseguidos con ellas. Los únicos que desempeñan un rol en el sistema de la corrupción pública son los que defienden intereses que entran en conflicto con los del resto de la sociedad (grupos de presión cuyas prácticas comerciales o económicas sólo benefician a un sector muy pequeño de la población y perjudican al resto o cuyo único objetivo es contribuir al crecimiento económico de su sector de actividad, grupos de empresarios que intentan instaurar un monopolio limitando la competencia....) $)^{90}$.

\subsection{Las dádivas}

La existencia de una "dádiva", como recompensa por la mediación, es uno de los requisitos esenciales del tráfico de influencias en la PALCO. El empleo de dicho término -en lugar de otros, como los de regalo, obsequio o presente- despeja, de entrada, cualquier duda sobre su carácter retributivo, esto es, su referencia a una relación de intercambio de prestaciones (precio a cambio de influencia).

\footnotetext{
${ }^{88}$ Sobre las relaciones entre lobbying y corrupción pública vid. CAMPOS Y GIOVANNONI (2006); ROCHA FIGUEIREDO (2012, pp. 23 y ss.).

${ }^{89}$ Vid. PEÑAILILLO, ARAÚZ ULLOA, SALDOMANDO Y BERTHIN (2009, p. 40).

${ }^{90}$ Defienden este criterio HARSTADT Y SVENSSON (2007, pp. 1 y ss.); ROCHA FIGUEIREDO (2012, pp. 25 y 26).
} 
A la hora de analizar su contenido y límites parece razonable acudir a los mismos criterios usados en sede de cohecho, teniendo en cuenta que las "dádivas" también forman parte de su descripción legal, en el epígrafe 7 de la primera parte de la PALCO, y que, entre ambas figuras, existe una estrechísima relación -puesto que utilizan técnicas de tipificación muy semejantes-. Los redactores del documento convalidan este punto de vista, al presentarlo como un instrumento imprescindible en la lucha contra la corrupción y para asegurar que sus resoluciones se dictan con la necesaria objetividad.

Al igual que sucede en la normativa internacional anti-corrupción, la diferencia entre el cohecho y el tráfico de influencias no parece estribar, por consiguiente, en el carácter económico o no económico del medio para conseguir una decisión favorable, sino en la presencia (o no) de un intermediario que se compromete a ejercer influencias (personales o jerárquicas) sobre el funcionario competente para adoptarla, que, por su parte, no percibe ventaja alguna, apareciendo, más bien, como una víctima inocente manipulada por aquel91. Todo lo anterior lleva a concluir, en definitiva, que la recompensa, en el tráfico de influencias, debería cubrir el amplísimo espectro de incentivos que dan vida al elemento de la dádiva en el cohecho: valores materiales (dinero, objetos preciosos, comidas, bebidas, vacaciones, utilización de determinados bienes aunque no se transfiera su propiedad...) e inmateriales (expectativas profesionales, información privilegiada, favores sexuales y de otro orden...).

En otro sentido, ninguna de las referencias o alusiones a la dádiva clarifica su límite económico, ni requiere, siquiera, que sea "indebida", a diferencia de lo indicado por el Informe Explicativo al texto de la CCE. Esa ausencia suscita la consabida cuestión de la relevancia de la teoría de la adecuación social a la hora de determinar la existencia de un delito de corrupción pública92.

Una conducta socialmente adecuada es una conducta tolerable, porque se la estima normal en un contexto social e histórico determinado. Es lógico hacer de ese criterio de tolerancia un elemento delimitador de la conducta típica, especialmente en aquellos casos en que la entrega o aceptación de la "ventaja" tiene un claro sentido de cortesía y forma parte, por ello, de los códigos de relación entre los ciudadanos y la Administración Pública en las sociedades democráticas. Cosa distinta es que su puesta en práctica resulte (como así es) todo menos sencilla, teniendo en cuenta que, por si sola, la distinción entre entregas socialmente inadecuadas (porque implican el enriquecimiento del funcionario) y pequeñas atenciones de bagatela o de reconocimiento social habitual no permite acotar, con la necesaria seguridad jurídica, el ámbito de lo penalmente relevante. Habrá de tener en cuenta otras consideraciones, personales y geográficas. Podemos comprobarlo, en particular, en relación con los incentivos ofrecidos a los médicos y a los profesionales sanitarios, en general (bolígrafos, muestras gratuitas, gastos relacionados con la asistencia a congresos para la formación...). Aunque existan normativas específicas sobre el tema, se suscitan casos límite y situaciones conflictivas, en las que no siempre queda claro si dichos sujetos incurren o no en responsabilidades penales. Ello ha llevado a algunos autores a señalar que lo importante, a efectos de comprobar la existencia del tráfico de influencias, es la capacidad que pueda poseer la ventaja para motivar al intermediario a ejercer la influencia, y no sólo su cuantía o el contexto en que se haya producido la entrega.

Entiendo que, a falta de referencia expresa, este el planteamiento que debe presidir la intelección del término "dádiva" en la PALCO.

\footnotetext{
${ }^{91}$ ABANTO VÁSQUEZ (2005, p. 22); GÓMEZ (2009, p. 92).

${ }^{92} \mathrm{La}$ relevancia de la teoría de la adecuación social en sede de los delitos de corrupción pública es independiente del concepto de dádiva que se acoja: ROCHA FIGUEIREDO (2012, p. 43). Exigir la naturaleza económica de los medios corruptores no evita, en absoluto, el tener que recurrir a ella. Vid., en cambio, de esta opinión, RODRÍGUEZ DELGADO (2006, p. 31).
} 


\section{Conclusiones}

En materia de tipificación del tráfico de influencias, la PALCO muestra considerables diferencias, en lo referente a su descripción y modalidades, con respecto a lo previsto en las convenciones internacionales anti-corrupción. Ello es explicable teniendo en cuenta que su objetivo final no es el de afrontar de una manera global o multilateral el tratamiento del delito, sino, meramente, el de armonizar las previsiones penales de los países del SICA. No es de extrañar, por ello, que uno de los principales obstáculos que ha debido afrontar es el representado por la heterogeneidad de las técnicas de tipificación elegidas por aquellos.

Entre los aspectos positivos de la PALCO debe mencionarse, ante todo, el de que transmita la idea de que nos enfrentamos a formas de corrupción graves y merecedoras de la máxima atención por parte de las autoridades estatales. Su punto de partida es, pues, el de que su criminalización no puede ser contemplada como una alternativa para los estados democráticos. Por contraste, conviene recordar aquí que dos de los principales instrumentos internacionales examinados (la CCE y la CUA) recurren a cláusulas de salvaguarda, que permiten a las partes no incorporar el delito a su derecho interno.

Al igual que en la mayoría de los instrumentos anti-corrupción, la disciplina del tráfico de influencias en la PALCO se asienta sobre la existencia de un ofrecimiento vinculado a un proceso de toma de decisiones o adopción de resoluciones en el ámbito de la Administración Pública. Sus redactores no parecen haberse hecho eco, por consiguiente, de las recomendaciones -contenidas, entre otros instrumentos, en la UNCAC y en otros textos elaborados en el marco de la OCDE y en el de la UE- que apuntan a la necesidad de flexibilizar los presupuestos de aplicación de los delitos de corrupción, para evitar la impunidad de ciertos comportamientos. En el art. 18 de la UNCAC, por ejemplo, no puede hallarse referencia alguna a las decisiones administrativas como objeto de la transacción, propiciándose, así, la tipicidad de las entregas económicas para influir en la consecución de decisiones de difícil o imposible identificación o para pagar gestiones relacionadas con cualquier asunto que pueda interesarle al comprador en el futuro.

El modelo de criminalización del tráfico acogido por la PALCO podrá merecer las críticas de quienes ponen por delante el carácter sistémico del tráfico de influencias, alineándolo con lo que denominan prácticas habituales en las economías de mercado93. Siguiendo esa línea de razonamiento, podría pensarse que para eliminarlo resulta imprescindible acudir a respuestas penales asimismo sistémicas, cuyo único requerimiento probatorio debería ser la demostración de que se ha producido una entrega económica por razón de la posición de influencia ocupada por el sujeto (SLINGERLAND, 2010, Pp. 9, II y I2). Esta hipótesis de tráfico de influencias in incertis actis genera, sin embargo, numerosas dudas, centradas, entre otros aspectos, en su incompatibilidad con las funciones sistemática y selectiva del tipo penal.

Efectivamente, resulta difícil renunciar al enfoque que defiende la PALCO (junto con la CCE y la CUA) sin hacer dejación, al propio tiempo, de los principios liberales del Derecho penal. Como indica KINDHÄUSER, los argumentos con que se sostiene la punibilidad del núcleo duro de un delito nunca deben traerse a colación para tipificar cualesquiera otros comportamientos próximos o conexos (KINDHÄUSER, 2007, p. I5). En tanto no aparezca vinculada a la realización de un proceso de toma de decisiones, la venta de la capacidad de influir (aunque sea real, cierta) no se corresponde con el campo de la corrupción en sentido penal (Rodríguez Delgado, 2006, p. 27). Para reprimir esa clase de conductas, en lugar de encomendarse al Derecho penal, los legisladores nacionales e internacionales deberían poner sus ojos, en primer lugar, en los sistemas de control interno de la actividad administrativa, como garantes «naturales» de su legalidad y trasparencia. Apelar al carácter disuasorio del Derecho penal no puede servir de coartada, en los Estados sociales y democráticos de Derecho, para mantener un sistema de sanciones desproporcionado, desequilibrado.

\footnotetext{
${ }^{93}$ SLINGERLAND (2010, pp. 9 y ss.); LI (2007, p. 2).
} 
La incriminación del tráfico de influencias sólo puede justificarse a partir de su peligrosidad —objetiva y subjetivapara la correcta valoración de los intereses en conflicto, propia de todo procedimiento administrativo, tal y como sugieren los redactores de la PALCO 94 . Es preciso, pues, que el intermediario posea realmente las influencias que dice (o sea, una capacidad real para influir), que esté decidido a emplearlas y que haya recibido una dádiva o promesa para hacerlo en relación con un asunto concreto. Los supuestos en que el intermediario engaña al solicitante, al no contar específicamente con la capacidad material de ejercer influencias o no poder o querer utilizarla para determinar el comportamiento del funcionario público en cuestión son similares, estructuralmente, a los que dan vida a la estafa $y$, como tal, deben calificarse ${ }^{95}$. El preocupante fenómeno de la corrupción pública ha de atajarse de la mano de estrategias preventivas y de control plenamente respetuosas con el principio de subsidiariedad del Derecho penal, y no con la criminalización de la aparente predisposición de los intermediarios a interferir en favor de los intereses de un particular o de un grupo de particulares.

La PALCO no deja traslucir ningún criterio para delimitar el tráfico de influencias y el lobbying. El lobby es un derecho ciudadano, cuyo ejercicio hace posible que los grupos y colectivos con menores recursos económicos, políticos y de comunicación puedan hacer valer sus puntos de vista e intereses en relación con las políticas públicas. El Informe Explicativo a la CCE sugiere la necesidad de que los legisladores nacionales definan los criterios para que los grupos de interés puedan actuar con legitimidad. El derecho comparado no ofrece, sin embargo, modelos homogéneos para abordar su tratamiento, destacando, por un lado, las experiencias peruana y mexicana, basadas en una regulación relativamente detallada de esta figura (Fundación Ecología y Desarrollo, 2013, pp. 45 y 46), y por el otro, la del Reino Unido, que ha optado por rechazar la regulación estatutaria y apoyarse, en cambio en la autorregulación de la industria. Se ha hablado, también, de un tercer modelo, el actualmente imperante en la UE, y que se basa en la información que se proporciona al público general sobre las relaciones entre los grupos de interés y la Comisión Europea, a fin de permitir el control externo, y en el establecimiento de un código ético aplicable a las personas contactadas por los grupos de presión y a ellos mismos (Fundación Ecología y Desarrollo, 2013, pp. 41 y 42 ).

Con esos referentes, las doctrinas nacionales han ido cifrando la distinción entre el ejercicio legítimo de influencias y el tráfico en datos no siempre compatibles con la normativa internacional. Así, la diferencia no puede estribar en que los grupos de presión busquen flexibilizar una regla (en su beneficio), mientras que el tráfico de influencias pretenda quebrantarla. Piénsese que muchos intentos de influencia se dirigen a la obtención de decisiones totalmente legítimas, al amparo del margen de apreciación subjetiva de que goza el funcionario. Tampoco puede recurrirse al criterio de que, mientras el lobbying puede producir o no el resultado deseado (en la medida en que se agota con la mediación), la corrupción siempre supone un acuerdo, en el que el pago depende de la obtención del resultado buscado. Ya se ha visto que la estructura del tráfico de influencias, en los instrumentos internacionales, no es la de un delito de resultado, consumándose con la venta de la influencia.

\footnotetext{
${ }^{94} \mathrm{Si}$, como indican BOGGINO Y ARGAÑA (2006, p. 18), cualquier estrategia de prevención de conflictos de intereses pasa por la definición de las situaciones que se consideran como tales, habrá de convenirse en que esas exigencias deben trasladarse con mayor intensidad, si cabe, al ámbito penal, presidido por los principios de tipicidad, ofensividad y proporcionalidad. En esa misma línea, ARELLANO, LEPORE, ZAMUDIO Y AGUILAR (2015) subrayan que "la definición del tráfico de influencias no considera aquellos problemas entre intereses privados y públicos que pudieran aparecer de forma potencial y/ o aparente", vinculándose únicamente con conflictos de intereses reales, es decir, "hechos ya consumados que han buscado y/o han logrado influir en el proceso decisorio de los funcionarios públicos para su beneficio personal o de sus particulares con los cuales estos tienen algún tipo de relación familiar, afectiva o laboral" ( $p$. 22).

${ }^{95}$ No puede compartirse, en este punto, el criterio de RODRÍGUEZ DELGADO, quien considera que todos los supuestos en que el traficante sabe, desde un primer momento, que a pesar de contar con las influencias nunca las iba a utilizar "sólo constituyen una mera infracción administrativa o una simple desobediencia", debiendo ser descartados como penalmente relevantes. Cfr. RODRÍGUEZ DELGADO (2006, pp. 29 y 30).
} 
No es, pues, la influencia per se, sino su legitimidad (la forma en que es ejercida) lo que permitirá efectuar ese deslinde. Mientras el lobbying se orienta a defender los intereses de una empresa, sector industrial o grupo de interesados, la corrupción pretende asegurar beneficios (fiscales, en concepto de subvenciones, contratas...) únicamente para el actor que ofrece el pago.

\section{Lista de referencias bibliográficas}

Abanto Vásquez, El tratamiento penal de los delitos contra la Administración Pública, Actas del XVII Congreso Latinoamericano, IX Iberoamericano, I Nacional de Derecho Penal y Criminología, Guayaquil, 2005, Pp. I ss.; Arellano, Lepore, Zamudio y Aguilar, Control de los conflictos de interés: Mecanismos organizacionales en la experiencia internacional y lecciones para México, México, CIDE, 20I5; Baena, Basco y de Michele, Una mirada independiente. Buenas prácticas en el seguimiento de las Convenciones Internacionales contra la corrupción por Organizaciones de la Sociedad Civil (OSC), Washington, Inter-American Development Bank, 20I0; Boggino y Argaña, Límites entre los intereses privados y el ejercicio de la función pública a la luz de las convenciones internacionales anticorrupción. Análisis de mecanismos, medidas y recomendaciones existentes, Asunción, Consejo Impulsor del Sistema Nacional de Integridad, 2006; Bonilla, Responsabilidad penal en el delito de tráfico de influencias cometido en la Administración Pública, Managua, Universidad Centroamericana, 20I I; Carr, Fighting corruption through regional and International conventions: a satisfactory solution?, European Journal of Crime, Criminal Law and Criminal Justice, 2007, 129 ss.; Fundación Ecología y Desarrollo, Programas y políticas públicas para la prevención de la corrupción en el ámbito privado. Buenas prácticas en América Latina y la Unión Europea, Madrid, FIIAPP, 2013; Gómez (coord.), Ética, transparencia y lucha contra la corrupción en la Administración pública. Manual para el ejercicio de la función pública, Buenos Aires, Gobierno de la República Argentina, 2009; Guimaray Mori, El delito de tráfico de influencias. Algunos apuntes sobre su tipicidad, en Montoya Vivanco (ed.), Estudios críticos sobre los delitos de corrupción de funcionarios en Perú, Lima, Instituto de Democracia y Derechos Humanos de la Pontifica Universidad Católica del Perú, 2009, I0I ss.; Harstad y Svensson, Bribes, lobbying and Development, American Political Science Review, 105, 20I I, I ss.; Hurtado Pozo, Interpretación y aplicación del art. 400 CP del Perú: Delito llamado de tráfico de influencias, en AA. VV. Interpretación y aplicación de la ley penal, Lima, Fondo Editorial PUCP, 2006, Pp. 288 ss.; Kindhäuser, Presupuestos de la corrupción punible en el Estado, la economía y la sociedad. Los delitos de corrupción en el Código penal alemán, Política Criminal, 3, 2007, Pp. I ss.; Klitgaard, Controlando la corrupción. Una indagación práctica para el gran problema social de fin de siglo, Buenos Aires, Sudamericana, 1994; Li, Peddling influence through well informed intermediaries, Riverside, USC FBE Applied Economics Workshop, 2007; Lombana Villalba, La tipificación del tráfico de influencias y del cohecho en España y en Colombia como forma de prevención de la corrupción pública, León, Universidad de León, 2013; Malem Seña, La corrupción. Aspectos éticos, económicos, políticos y jurídicos, Barcelona, Gedisa, 2002; Montinola y Jackman, Sources of corruption: a cross-country study, British Journal of Political Science, 32, 2002, I 47 ss.; Olken y Pande, Corruption in developing countries, Annual Review of Economics, 20I 2-4, 479 y ss.; 
Ora Sosé, La Ley 29703 y la reforma de algunos delitos contra la Administración Pública, Estudio Oré Guardia, Boletín 28, 4 de julio de 20II, pp. II ss.; Peñailillo, Araúz Ulloa, Saldomando y Berthin, Diagnóstico de la corrupción en Nicaragua, Managua, Fondo conjunto de donantes para la anticorrupción, 2009; Peñailillo, ¿Cuán preparados estamos para evaluar la real implementación de las convenciones anticorrupción?. Lecciones desde las Américas, Bergen, U4 Anti-Corruption Resource Centre, 2009; del Pino, Políticas de lucha contra la corrupción en Centroamérica y República Dominicana, en Colino, Molino, Parrado y Pino (ed.), Avances y obstáculos en el fortalecimiento del Estado en Centroamérica y República Dominicana: un análisis de la capacidad institucional, Madrid, INAP, 2007, I ss.; Reátegui Sánchez, Los delitos de corrupción de funcionario y delincuencia organizada, RDPA, 2004-2, I ss.; Rocha Figueiredo, Tráfico de influencia: análise crítica da incriminaçao, Lisboa, Universidade Católica Portuguesa, 2012; Rodríguez Delgado, El final de la historia: ¡El interesado en el tráfico de influencias e simpune!”, lus et Veritas, 33, 2006, I ss.; Slingerland, Trading in influence: corruption revisited, Toulouse, EGPA Study Group on Ethics and Integrity of Governance, 2010; Soreide, Corruption and competition. Fair market as an anticorruption device, The Nagoya Journal of law and politics, 258, 20I4, 239 ss.; Tanzi y Davoodi, Corruption, public investment, and growth, Washington, IMF Working Paper, 1997; Tanzi, Corruption Around the World: Causes, Consequences, Scope, and Cures, en Abed y Gupta, Governance, Corruption \& Economic Performance, International Monetary Fund, Washington, 2002, 32 ss.; Tay y Seda, The enemy within: combating corruption in Asia, Singapore, Cavendish Square Publishing, 2003; Vargas-Hernández, The multiple faces of corruption: typology, forms and levels, Studies of Changing Societies, I(6), 20I2, 13 ss.; Wesberry, Obstáculos institucionales que limitan las funciones de los organismos gubernamentales de combate a la corrupción en América Latina, Caracas, Centro Latinoamericano de Administración para el Desarrollo, 2004. 